\title{
Variants of Energy Efficient Clustering Protocols for Wireless Sensor Networks
}

\author{
Er. Gautami Daalia \\ Research Scholar, DAV University, Jalandhar, India \\ E-mail: daalia.gautami@gmail.com \\ Er. Ridhi Kapoor \\ Assistant Professor, DAV University, Jalandhar, India \\ E-mail: ridhikapoor89@gmail.com
}

\begin{abstract}
The energy resource-contrived is the most difficult aspect of WSN and that energy cannot be recharged. When every sensor node is needed to move ahead the data packet to the sink node, the problem emerges there. Through unmoving, listening and retransmitting, the accessible energy in every node could be lost in this procedure because of collisions as well as overhearing. Network topology management and energy minimization is done due to Cluster-based WSN routing protocols. In clustering in WSN, sensor nodes are sorted into little disjoint clusters, where every cluster has an organizer referred as $\mathrm{CH}$. In this paper, energy efficient clustering techniques related to WSNs are discussed and comparative analysis is also performed.
\end{abstract}

Index Terms-Wireless Sensor Networks, Clustering, Energy-efficiency, Mobile sink, Homogeneity, Heterogeneity.

\section{INTRODUCTION TO WSN}

WSNs are getting popular in real world and in real life uses. Wireless sensor networks with detecting, processing, and wireless communication abilities contain small nodes In wireless sensor networks, sensors are distributed in an ad hoc manner. These sensors sense some physical fact by working with one other and then to get significant results, the collected data is processed. Wireless sensor networks form an infrastructure less wireless network where nodes are independent and self-organizing. It is Low-power microscopic sensors with wireless communication capability. Wireless sensor networks consist of protocols and algorithms with self-organizing capabilities Data is processed by all sensor nodes and transferred it to base station also called sink as shown in fig.1. In WSNs these sensor nodes are energy restricted because of confined battery resource. So using the battery in an efficient way becomes critical issue. A number of protocols play an important role to reduce useful energy consumption.

Direct connection and multi-hop data transmission used initially. But because of confined power of sensor nodes these methods don't work effectively. Clustering is a technique where nodes are organized into clusters that are useful in achieving energy efficiency. All nodes hav- ing a place with the same group send their information to $\mathrm{CH}$. Then $\mathrm{CH}$ collects information and sends collected information to BS where the end-user can access the data. It has been seen that large amount of energy consumption is reduced by using clustering scheme. But in clustering scheme death time of head node was too early.

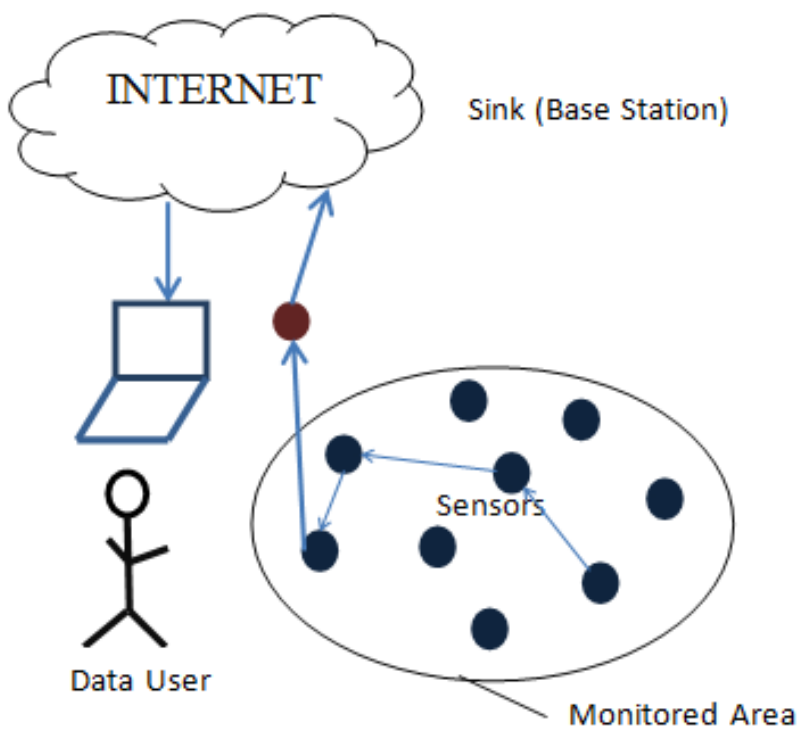

Fig.1. Wireless Sensor Network

The rest of the paper is organized as follows: Section II briefly explains the clustering in Wireless Sensor Network (WSN). Section III discusses the need for energy efficiency in WSN. Section IV presents the existing related work. Section V sheds light over many clustering protocols. The conclusions and future scope are stated in Section VI.

\section{CLUSTERING IN WSN}

Clustering method is among the well-liked techniques in which nodes settle on a Cluster Head $(\mathrm{CH})$ for communication. Every node spread its information to $\mathrm{CH}$, where it aggregate information and deliver to the Base Station (BS) as shown in fig.2. Just some nodes are utilized to spread at huge distance; therefore not so much 
energy is expended. To lessen the particular network traffic coming from node to base station is the leading idea of clustering. Nodes have minimal battery lifestyle in like manner to defend energy, clustering technique seemed to be unveiled, from which out of many nodes some of nodes turn into cluster head and they manage the whole network. Cluster head is usually a node that's reliable for preserving cluster, collect information from nodes in the cluster and then they talk to sink. By utilizing clustering process it's been observed that there is huge quantity of energy that's been rescued.

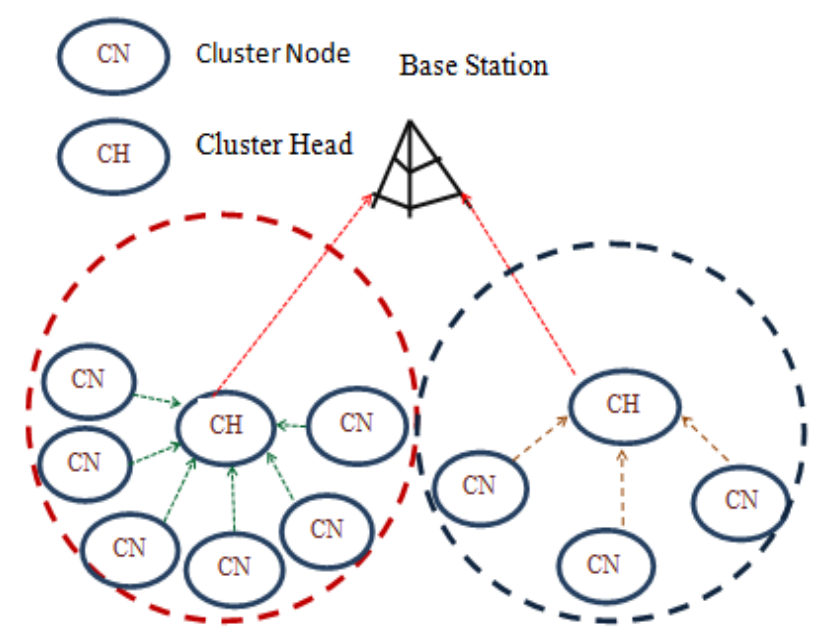

Fig.2. Clustering Hierarchy

In static clustering approach some plans were being adopted to choose the cluster head. The cluster is generated along with cluster head is determined. Until the head node dead, the cluster was statically operated. The energy in the cluster head node will rapidly decrease because cluster head node has more tasks. The loss moment ended up being head node ended up being far too regular inside static clustering approach. It is valuable in achieving energy efficiency. To optimize energy consumption in WSN, it is a key technique.

In the usual hierarchical routing protocols, based on the comparison between a random numbers produced by sensor nodes and a definite threshold, cluster heads are chosen. From their respective clusters, these cluster heads collect and aggregate the information and to the base station (BS) it is delivered. The energy conservation is greatly reduced due to the aggregation of the data at $\mathrm{CHs}$ by reducing the total information messages sent to the BS in the network. For transmitting data relatively over a short distance, the $\mathrm{CHs}$ behave as local sink for data.

There are 2 types of network in which clustering can be done. It is homogeneous and heterogeneous networks. Preliminary energy of all nodes is same in homogeneous systems while all nodes have different original energy in heterogeneous networks.

\section{NEED FOR ENERGY-EFFICIENCY IN WSN}

In WSN, the nodes are thoroughly energy controlled, and battery substitution is frequently not practical, that is why energy efficiency is an important outline reason in the vast majority of the study related to wireless sensor networks. For reducing the quantity of information that is actually sent to the base station, cluster heads also offer as synthesis factors for aggregation of data. The sensor nodes in wireless networks are controlled by restricted energy that is why it is important to improve the lifetime in wireless sensor networks. The way to improve WSN lifetime is to extend energy-efficient protocol for reducing energy conservation. There is limited energy supply in sensor nodes and their recharge is impractical.

Due to confined energy in sensor nodes, energy is incredibly vital problem in WSN. So clustering technique was introduced to preserve energy, in which out of a huge number of nodes some of nodes turn into cluster heads and they also take care of the entire network. That network is composed of a wide quantity of nodes which often intellect information through the impossibly unreachable place as well as send out their particular information to a base station called a sink. Since, sensor nodes usually are energy controlled; several long-distance transmissions must be held to the very least which is able to expand the network life.

Therefore, direct communications regarding nodes and also the base station will not be confident. To partition the network into a number of clusters is a profitable move, each electing one node as its cluster head. The particular cluster head accumulates information through detectors inside the cluster which is put together in addition to carried to the base station. Hence, just few nodes are necessary in order to send out information within the long distance in addition to other nodes which should perform only short-distance exchanges. With this more energy can be preserved in addition to the extension of network life span. Many energy-efficient routing methods are created utilizing the clustering development process in which cluster heads are usually chosen.

\section{RELATED WORKS}

As stated in previous section, the much focus is required on energy efficiency of Wireless Sensor Network. In recent years, many researchers have contributed in accomplishing this need and provided many energy efficiency protocols. Some of the existing energy efficient clustering techniques are discussed below and their comparative analysis is shown in Table 1.

Izadi et al. [1], proposed a self configurable clustering mechanism $(\mathrm{SCCH})$ to find that $\mathrm{CHs}$ which are disordered and then that nodes will be replaced by others. In spite of important improvements in (WSNs), energy preservation in the network is essentially the most crucial aspect. One particular method commonly used to be able to increase the actual network life span is via collecting information on the cluster heads (CHs). Nonetheless, chances arises that the $\mathrm{CHs}$ might are unsuccessful and process wrongly because of a variety of factors for example lack of stability in power. They proposed this method (SCCH) to reduce the data loss and allowed data to transfer correctly. 
Jenq-Shiou et al. [2], proposed Regional Energy Aware Clustering with Isolated Nodes (REAC-IN). It is a new local energy aware clustering method. It uses isolated nodes for WSNs. Here on the basis of weight, $\mathrm{CHs}$ are decided. The remaining energy of every sensor and the local average energy of all sensors in every cluster defined the weight. They proposed this method to increase the energy efficiency of WSN.

Khediri et al. [3], proposed optimization Low Energy Adaptive Clustering Hierarchy (O- LEACH). By choosing cluster according to the remaining energy they improved existing LEACH and LEACH-C. They proposed this method to limit energy consumption.

Thakkar et al. [4], proposed Energy Delay Index for Trade-off (EDIT) which is a routing algorithm. In this both objectives (energy and delay) are optimized. A large number of communication and energy nodes are deployed in WSN. Once these are deployed in an atmosphere, there is a difficulty to replace and recharge the batteries of WSN nodes. Therefore, load balancing must be done for communication between the WSN nodes. Hence, to increase the network life span and to provide data to sink with a limited delay, this EDIT protocol is proposed.

Wagh et al. [5], proposed genetic algorithm of evolutionary approach to increase the network life and also for low power operation of the nodes. By utilizing auction data of node i.e. its local battery power, topology strength and additional battery help, selection of cluster head is done intelligently in it. The multi objective parameters are considered in it.

Bijendra Kumar et al. [6], proposed Ant Colony Optimization (ACO). It is a network routing technique which is based on swarm intelligence. In this LEACH protocol is applied on ACO algorithm in Wireless Sensor Networks. It is proposed to increase energy efficiency and to increase the entire life of network by routing the information packets in sensor networks.

Mahajan et al. [7], proposed a Stable Election Protocol (SEP). For selecting the optimal cluster head, this new dynamic strategy is proposed. In this protocol, the node which has the maximum energy among all of the accessible nodes in that particular cluster is selected as a cluster head. The heterogeneity of nodes is considered in this proposed protocol where nodes are divided among normal, intermediate and advance nodes. Different improved probability density functions are selected, to handle the heterogeneity of the nodes,

Izadi et al. [8], proposed a type-2 fuzzy based selfconfigurable cluster head selection $(\mathrm{SCCH})$ approach. In this cluster backup approach is considered with the selection criteria of cluster head. It is proposed to increase energy efficiency and to increase the life of the whole network through aggregating data at the cluster head.

Mhemed et al. [9], proposed the Fuzzy Logic Cluster Formation Protocol (FLCFP). In this during the formation of cluster, Fuzzy Logic Inference System (FIS) is used. They proposed this for reducing energy consumption and multiple parameters can be used. It increases the network lifespan.
Kim et al. [10], proposed CHEF-Cluster Head Election mechanism using Fuzzy logic. They proposed this for increasing the life of the Sensor Networks, collecting and calculating overheads can be reduced.

Jin-Shyan et al. [11], proposed a clustering approach based on fuzzy-logic with an extension to the energy predication. It had been produced by similarly circulating the workload to improve the lifespan of WSNs. Its performance is a lot more than other distributed algorithms. It is believed that the approach presented in this paper could possibly be more put on to large-scale wireless sensor networks.

Ran, Ge et al. [12], have done improvement in LEACH protocol using Fuzzy Logic (LEACH-FL). LEACH is one of the very popular clustering method. It chooses a cluster head $(\mathrm{CH})$ centred on a probability model. This protocol has improves LEACH protocol using Fuzzy Logic (LEACH-FL), which considered battery level, distance and node density. The proposed technique has been proved creating a better selection as it increases the lifespan of the network.

Hussain et al. [13], considers the Fuzzy input variables for choosing cluster head. Cluster head is the key entity, and all the responsibility for the data transmission depends on this single entity. The authors not just worked on the criterion of choosing cluster head but additionally suggested the cluster back up method, to ensure that in case there is cluster failure, the system however performs with in an effective way. This protocol reduces the power consumption in the nodes and increases the lifespan of the whole network.

Denis Riordan et al. [14], proposed fuzzy logic method to select cluster head which was depend upon three parameters - energy, concentration and centrality. It minimizes the energy consumption and increase the life span of the network.

Izadi et al. [15], has analyzed and mentioned the certain requirements, important issues, and open research issues on QoS management in WSNs. Promoting quality of service (QoS) is likely to be of critical value for pervasive WSNs that offer because the network infrastructure of varied applications.

\section{Clustering Protocols}

Some more existing energy efficient clustering techniques are discussed below-

A. Leach- Low Energy Adaptive Clustering hierarchy with Deterministic $\mathrm{CH}$ Selection is the first well known clustering protocol whose production depends upon a clustering method for picking $\mathrm{CHs}$ by utilizing optimal probability[1]. Their functioning is dependent on periodic randomized shifts of the $\mathrm{CH}$ within the cluster range $(0,1)$. The node becomes a $\mathrm{CH}$ for the current round if the random number is less than the pre-determined threshold value. The authors have succeeded in their efforts to perform a reduction in dissemination of energy contrasted with direct communication and transmission protocols. 
Nonetheless, LEACH cannot promise a satisfactory $\mathrm{CH}$ distribution because in this technique the number of clusters is already defined. Moreover, because there is lack of help in deploying network with a wide number of sensor nodes, the method cannot be utilized in a large area. Additionally, LEACH impacts from significant energy usage when it is no $\mathrm{CH}$ chosen in few rounds.

Table 1. Comparative analysis of some existing energy efficiency clustering techniques in WSN

\begin{tabular}{|c|c|c|c|c|c|}
\hline $\begin{array}{c}\text { Reference } \\
\text { No. }\end{array}$ & Title of the paper (Year) & Issues & Technique & Benefits & Limitations \\
\hline$[1]$ & $\begin{array}{l}\text { An Alternative Clustering } \\
\text { Scheme in WSN(2015) }\end{array}$ & $\begin{array}{l}\text { Energy efficien- } \\
\text { cy, } \\
\text { Clustering, } \\
\text { Cluster heads } \\
\text { fails }\end{array}$ & $\begin{array}{l}\text { Self configurable clus- } \\
\text { tering protocol }(\mathrm{SCCH})\end{array}$ & $\begin{array}{l}\text { Maximize lifetime, } \\
\text { Reduce overheads and } \\
\text { reduce packet loss }\end{array}$ & $\begin{array}{l}\text { No intercluster } \\
\text { data aggregation }\end{array}$ \\
\hline [2] & $\begin{array}{l}\text { Energy Efficient Clustering } \\
\text { Scheme for Prolonging the } \\
\text { Lifetime of Wireless Sensor } \\
\text { Network With Isolated } \\
\text { Nodes }(2015)\end{array}$ & $\begin{array}{l}\text { Energy } \quad \text { Effi- } \\
\text { ciency }\end{array}$ & $\begin{array}{l}\text { Regional energy aware } \\
\text { clustering with isolated } \\
\text { nodes(REAC-IN) }\end{array}$ & $\begin{array}{l}\text { Prolonging network } \\
\text { lifetime, Solve node } \\
\text { isolation problem, } \\
\text { Improves cluster head } \\
\text { selection process }\end{array}$ & NA \\
\hline [3] & $\begin{array}{l}\text { A new approach for cluster- } \\
\text { ing in wireless sensors net- } \\
\text { works based } \\
\operatorname{LEACH}(2014)\end{array}$ & $\begin{array}{l}\text { Energy Effi- } \\
\text { ciency, Lifetime } \\
\text { of network, } \\
\text { Node failure }\end{array}$ & $\begin{array}{l}\text { Optimization Low } \\
\text { Energy Adaptive Clus- } \\
\text { tering Hierarchy(O- } \\
\text { LEACH })\end{array}$ & $\begin{array}{l}\text { Longer stability of } \\
\text { network, Reducing } \\
\text { overheads, Improve } \\
\text { lifetime and stability } \\
\text { of nodes }\end{array}$ & $\begin{array}{l}\text { If base station is } \\
\text { misplaced, the } \\
\text { quality and } \\
\text { energy con- } \\
\text { sumption be- } \\
\begin{array}{l}\text { come more } \\
\text { effective }\end{array}\end{array}$ \\
\hline [4] & $\begin{array}{l}\text { Cluster head election for } \\
\text { energy and delay constraint } \\
\text { applications of wireless sen- } \\
\text { sor network(2014) }\end{array}$ & $\begin{array}{l}\text { Network Life- } \\
\text { time, } \\
\text { Delay }\end{array}$ & $\begin{array}{l}\text { Energy Delay Index for } \\
\text { Trade-off (EDIT) }\end{array}$ & $\begin{array}{l}\text { Optimize energy and } \\
\text { delay }\end{array}$ & NA \\
\hline [6] & $\begin{array}{l}\text { Ant Based Cluster Head } \\
\text { Election Algorithm in Wire- } \\
\text { less Sensor Network to } \\
\text { Avoid Redundancy(2014) }\end{array}$ & $\begin{array}{l}\text { Limited power, } \\
\text { Shorter lifetime }\end{array}$ & $\begin{array}{l}\text { Novel routing approach } \\
\text { based on ACO(Ant } \\
\text { colony optimization } \\
\text { algorithm) }\end{array}$ & $\begin{array}{l}\text { Increase energy effi- } \\
\text { ciency, Increase net- } \\
\text { work lifetime }\end{array}$ & NA \\
\hline [7] & $\begin{array}{l}\text { Improving the stable period } \\
\text { of WSN using dynamic Sta- } \\
\text { ble leach Election Proto- } \\
\text { col(2014) }\end{array}$ & Stability period & $\begin{array}{l}\text { Stable Election Proto- } \\
\text { col } \\
\text { (SEP) }\end{array}$ & $\begin{array}{l}\text { Heterogeneity of the } \\
\text { nodes, Increase the } \\
\text { overall network life- } \\
\text { time }\end{array}$ & NA \\
\hline [8] & $\begin{array}{l}\text { A new energy efficient clus- } \\
\text { ter-head and backup selection } \\
\text { scheme in WSN(2013) }\end{array}$ & $\begin{array}{l}\text { Energy Conser- } \\
\text { vation }\end{array}$ & $\begin{array}{l}\text { Type-2 fuzzy based } \\
\text { self-configurable clus- } \\
\text { ter head selection } \\
(\mathrm{SCCH}) \text { approach }\end{array}$ & $\begin{array}{l}\text { Cluster Backup, Han- } \\
\text { dle communication } \\
\text { uncertainty, } \\
\text { Expand network } \\
\text { lifetime }\end{array}$ & NA \\
\hline [9] & $\begin{array}{l}\text { An energy efficient fuzzy } \\
\text { logic cluster formation proto- } \\
\text { col in wireless sensor net- } \\
\text { works(2012) }\end{array}$ & $\begin{array}{l}\text { Energy Conser- } \\
\text { vation, Cluster- } \\
\text { ing, Cluster } \\
\text { formation }\end{array}$ & $\begin{array}{l}\text { Fuzzy Logic Cluster } \\
\text { Formation Protocol } \\
\text { (FLCFP), which uses } \\
\text { Fuzzy Logic Inference } \\
\text { System (FIS) }\end{array}$ & $\begin{array}{l}\text { Network Lifetime } \\
\text { increases, Clustering } \\
\text { adds flexibility, Re- } \\
\text { duces energy con- } \\
\text { sumption }\end{array}$ & NA \\
\hline$[11]$ & $\begin{array}{l}\text { Fuzzy-logic-based clustering } \\
\text { approach for wireless sensor } \\
\text { networks using energy predi- } \\
\text { cation(2012) }\end{array}$ & $\begin{array}{l}\text { Distribution of } \\
\text { Workload }\end{array}$ & $\begin{array}{l}\text { Fuzzy-logic-based } \\
\text { clustering approach }\end{array}$ & $\begin{array}{l}\text { Increase lifetime of } \\
\text { WSN, Load is equally } \\
\text { distributed among } \\
\text { nodes }\end{array}$ & NA \\
\hline [12] & $\begin{array}{l}\text { Improving on LEACH proto- } \\
\text { col of wireless sensor net- } \\
\text { works using fuzzy log- } \\
\text { ic }(2010)\end{array}$ & Energy & $\begin{array}{l}\text { LEACH protocol using } \\
\text { Fuzzy Logic (LEACH- } \\
\text { FL) }\end{array}$ & $\begin{array}{l}\text { Elects cluster head } \\
\text { based on probability }\end{array}$ & NA \\
\hline$[10]$ & $\begin{array}{l}\text { CHEF: cluster head election } \\
\text { mechanism using fuzzy logic } \\
\text { in wireless sensor net- } \\
\text { works(2008) }\end{array}$ & Energy & $\begin{array}{l}\text { CHEF-Cluster Head } \\
\text { Election mechanism } \\
\text { using Fuzzy logic }\end{array}$ & $\begin{array}{l}\text { Reduce overheads, } \\
\text { Prolonging the life- } \\
\text { time of sensor net- } \\
\text { works }\end{array}$ & NA \\
\hline
\end{tabular}

B. Leach-FL- The performance of the networks is somewhat increased by making use of Type 1 fuzzy system in distributed protocols [1]. There is also a change in LEACH i.e. LEACH-FL that uses a comparable way to deal with. In this protocol, the CHs which have higher chance are chosen as BS. In spite of having some drawbacks, its results have been better than LEACH protocol. Authors have introduced CHEF routing method, to remove the problem of centralized algorithms. The lifetime of the network is clearly extended by CHEF. However, few neighbor nodes as $\mathrm{CHs}$ are selected.

C. GCHE-FL- Another protocol is Gateway and $\mathrm{CH}$ election in heterogeneous WSN by fuzzy logic (GCHE-FL)[1]. For calculating the opportunity of sensors for becoming a gateway and $\mathrm{CH}$, this method used two fuzzy based elections. The qualified nodes are chosen considering its energy and range to the BS, in the first election (Gateway Election). Remaining energy of every node and cluster range is 
utilized for the next election (CH Election). Cluster distance is the Sum of distances between cluster members.

D. DEEC-Yet Another proposed technique for heterogeneous WSNs is Distributed energy efficient clustering (DEEC) algorithm [1]. In DEEC, probabilistic models which are based on remaining energy of each node and the average energy of the network are used for picking CHs. Centered on their remaining energy, the duty of $\mathrm{CHs}$ is rotated between every one of the nodes in the network. The sum total energy and the system lifespan are to be notified by all the deployed nodes. BS broadcasts that data. Next to recognize that if it can be a $\mathrm{CH}$ on that round, every node matches the acquired data and their remaining energy against a predefined threshold.

E. SCCH-Another proposed technique is Self configurable clustering protocol $(\mathrm{SCCH})[1]$. The sensor nodes are first clustered by $\mathrm{SCCH}$. Then $\mathrm{CHs}$ are selected. A fuzzy process and considered regional data of each sensor node is utilized, to define CHs. The eligibility of sensor nodes to become $\mathrm{CHs}$ is presented as productivity of the system. Then all the nodes in the system are compared and they tested its eligibilities against others. A node introduces itself as a $\mathrm{CH}$ which includes the maximum eligibility and another node as BCHs. Consequently, the CMs ensure that for their CHs there's generally BCHs. Thus, the $\mathrm{CMs}$ may alter the $\mathrm{BCH}$ with the permanent $\mathrm{CH}$ failure in case there is $\mathrm{CH}$ failure. By relating the behavior of the SCCH against a fuzzy and a famous non-fuzzy method, the claim was proved. It increases network lifespan by lowering overhead in WSNs.

\section{A. Limitations in Earlier Work-}

From the literature survey, it has been observed that much research is done on various parameters but still there are some areas which need to be more focused by researchers. Subsequent section contains various limitations found in existing literature:-

1. The effect of heterogeneity of nodes is not prominently brought into practice in the existing work.

2. Not much work has been done on implementing Evolutionary optimization algorithms for inter- cluster data aggregation.

3. The effect of mobile sink based WSNs are also not considered in the majority of existing literature.

4. The background of compressive sensing is also not much practice in the existing work.

5. Not much work has been focused on reformation of clusters based on fitness value of every node which is recomputed after each iteration.

\section{CONCLUSION AND Future SCOPE}

WSNs can increase the energy efficiency by using an appropriate clustering algorithm for combination of sensor nodes. Some work has focused on evaluating the per- formance of fuzzy logic based clustering protocol. But fuzzy logic based clustering protocol has not considered the effect of heterogeneity of nodes, the use of evolutionary optimization algorithm for inter-cluster data aggregation is also ignored and limited to stationary sink based environment. Therefore in order to remove these issues, evolutionary optimization algorithm based data aggregation protocol will be proposed which will utilise Fuzzy logic to develop cluster heads, evolutionary optimization algorithm for effective inter-cluster data aggregation for stationary and mobile sink based environment.

\section{REFERENCES}

[1] Izadi, Davood, JemalAbawajy, and Sara Ghanavati. "An Alternative Clustering Scheme in WSN." (2015).

[2] Leu, Jenq-Shiou, Tung-Hung Chiang, Min-Chieh Yu, and Kuan-Wu Su. "Energy Efficient Clustering Scheme for Prolonging the Lifetime of Wireless Sensor Network with Isolated Nodes." Communications Letters, IEEE 19, no. 2 (2015): 259-262.

[3] Khediri, Salim EL, NejahNasri, Anne Wei, and AbdennaceurKachouri. "A new approach for clustering in wireless sensors networks based on LEACH." Procedia Computer Science 32 (2014): 1180-1185.

[4] Thakkar, Ankit, and KetanKotecha. "Cluster head election for energy and delay constraint applications of wireless sensor network." Sensors Journal, IEEE 14, no. 8 (2014): 2658-2664.

[5] Wagh, Sushama, and Ranga Prasad. "Maximizing lifetime of wireless sensor networks using genetic approach." In Advance Computing Conference (IACC), 2014 IEEE International, pp. 215-219. IEEE, 2014.

[6] Sharma, Toshi, Bijendra Kumar, Karan Berry, Akanksha Dhawan, Rahul Singh Rathore, and Vishalakshi Gupta. "Ant Based Cluster Head Election Algorithm in Wireless Sensor Network to Avoid Redundancy." In Communication Systems and Network Technologies (CSNT), 2014 Fourth International Conference on, pp. 83-88. IEEE, 2014.

[7] Mahajan, Laveena, and Neelam Sharma. "Improving the stable period of WSN using dynamic Stable leach Election Protocol." In Issues and Challenges in Intelligent Computing Techniques (ICICT), 2014 International Conference on, pp. 393-400. IEEE, 2014.

[8] Izadi, Davood, JemalAbawajy, and Sara Ghanavati. "A new energy efficient cluster-head and backup selection scheme in WSN." In Information Reuse and Integration (IRI), 2013 IEEE 14th International Conference on, pp. 408-415. IEEE, 2013.

[9] Mhemed, Rogaia, NaumanAslam, William Phillips, and Frank Comeau. "An energy efficient fuzzy logic cluster formation protocol in wireless sensor networks." Procedia Computer Science 10 (2012): 255-262.

[10] Kim, Jong-Myoung, Seon-Ho Park, Young-Ju Han, and Tai-Myoung Chung. "CHEF: cluster head election mechanism using fuzzy logic in wireless sensor networks." In Advanced communication technology, 2008. ICACT 2008. 10th international conference on, vol. 1, pp. 654-659. IEEE, 2008.

[11] Lee, Jin-Shyan, and Wei-Liang Cheng. "Fuzzy-logicbased clustering approach for wireless sensor networks using energy predication." Sensors Journal, IEEE12, no. 9 (2012): 2891-2897.

[12] Ran, Ge, Huazhong Zhang, and Shulan Gong. "Improving on LEACH protocol of wireless sensor networks using 
fuzzy logic." Journal of Information \& Computational Science 7, no. 3 (2010): 767-775.

[13] Hussain, E., Xiong Zhang, Li Chao, and S. A. Bugti. "Fuzzy based smart selection of cluster head with backup support in wireless sensor network." InComputing and Networking Technology (ICCNT), 2012 8th International Conference on, pp. 235-239. IEEE, 2012.

[14] Gupta, Indranil, Denis Riordan, and SrinivasSampalli. "Cluster-head election using fuzzy logic for wireless sensor networks." In Communication Networks and Services Research Conference, 2005. Proceedings of the 3rd Annual, pp. 255-260. IEEE, 2005.

[15] Izadi, Davood, JemalAbawajy, and Sara Ghanavati. "Quality control of sensor network data." In Advances in Automation and Robotics, Vol. 1, pp. 467-480. Springer Berlin Heidelberg, 2012.

\section{Authors' Profiles}

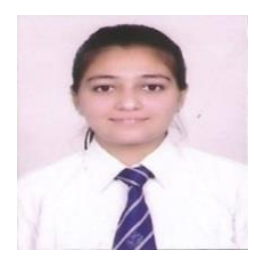

Er. Gautami Daalia (17 ${ }^{\text {th }}$ April, 1993). She has done B.tech-CSE from PTU campus (Amritsar) and pursuing Mtech in CSE from DAV University, Jalandhar. She is a research scholar in CSE department and working in the domain of WSN.

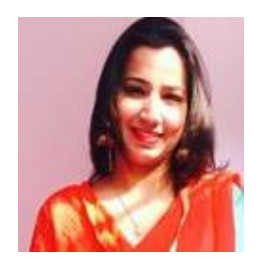

Er. Ridhi Kapoor $\left(4^{\text {th }}\right.$ December, 1989) She has done B.tech in CSE from PTU campus (Amritsar) and M.tech in CSE from GNDU campus (Amritsar). She has done her research in Distributed Databases and now working in the domain of WSN. She is working as an assistant professor in CSE department at DAV University, Jalandhar.

How to cite this paper: Er. Gautami Daalia, Er. Ridhi Kapoor,"Variants of Energy Efficient Clustering Protocols for Wireless Sensor Networks", International Journal of Computer Network and Information Security(IJCNIS), Vol.8, No.11, pp.52-57, 2016.DOI: 10.5815/ijcnis.2016.11.06 